\section{The survival story of a diabetic ketoacidosis patient with blood sugar levels of $1985 \mathrm{mg} / \mathrm{dL}$}

Dear Sir,

As you are aware, diabetic ketoacidosis (DKA) and hyperglycemic hyperosmolar state (HHS) are two of the acute and critical conditions faced by patients with diabetes mellitus (DM). Previously, DKA was considered as a hallmark of type $1 \mathrm{DM}$, while HHS of type $2 \mathrm{DM}$. But now, DKA is also seen among type $2 \mathrm{DM}$ patients.

DKA is characterised by hyperglycemia, ketosis and metabolic acidosis. It is the result of an absolute or relative deficiency of insulin with excess of counter regulatory hormones like glucagon, catecholamines, growth hormone and cortisol. The increased release of fatty acid from adipocytes leads to ketosis. The event is precipitated by inadequate insulin administration, infections (pneumonia, urinary infection, gastroenteritis), infarction (cerebral, mesenteric, coronary, peripheral) or drugs (cocaine). These patients present with nausea, vomiting, thirst, polyuria and dyspnoea. Clinically, they are dehydrated, tachypnoeic and may be comatose. Tachycardia, hypotension and abdominal pain are other findings. Investigation reports show elevated blood sugar levels $(250-600 \mathrm{mg} / \mathrm{dL})$, strong presence of plasma and urinary ketones and low arterial $\mathrm{pH}(6.8-7.3){ }^{1}$

This is a case of an 82 year old lady who is a known case of DM (on insulin therapy), hypertension (on amlodipine $5 \mathrm{mg}$ once daily) and dyslipidemia (on atorvastatin $20 \mathrm{mg}$ at night). She has been on these medications for the past 15 years. She had history of fever and burning micturition since 2 days; and during this period she skipped her insulin. On presentation, she was unconscious. Her heart rate was $120 /$ minute, blood pressure $90 / 60 \mathrm{mmHg}$, temperature $99^{\circ} \mathrm{F}$, respiratory rate 32 / minute with saturation $96 \%$ (room air). She was dehydrated. Her systemic examinations were normal. Her laboratory investigations showed leucocytosis (13000 cells $/ \mathrm{cmm})$ with neutrophilia (92\%), deranged renal functions (urea $62 \mathrm{mg} / \mathrm{dL}$ and creatinine $1.8 \mathrm{mg} / \mathrm{dL}$ ) and blood sugar levels $1985 \mathrm{mg} / \mathrm{dL}$. Her urine ketones were positive (4+) and urine microscopy showed plenty of pus cells. Her arterial blood gas analysis showed metabolic acidosis with $\mathrm{pH}$ 6.9, $\mathrm{pCO}_{2} 15 \mathrm{mmHg}, \mathrm{HCO}_{3} 10 \mathrm{mEq} / \mathrm{L}$.
Access this article online

Website:

http://nepjol.info/index.php/AJMS

DOI: 10.3126/ajms.v8i4.17251

E-ISSN: 2091-0576

P-ISSN: 2467-9100

Her electrolytes, liver functions, chest Xray and ECG were normal. Her CT brain showed age related atrophic changes. She was managed with intravenous fluids and insulin infusion (according DKA protocol). Injection ceftriaxone was administered for urinary infection. By day 3 of admission, patient became conscious and well oriented. Her vitals stabilized. Blood sugar levels were normalized to 100 to $150 \mathrm{mg} / \mathrm{dL}$ and fixed doses of insulin were started. Her urine culture grew Klebsiella and antibiotics were changed to Piperacillin plus Tazobactam (according to culture and sensitivity reports). She was discharged in stable condition on day 10 of admission.

As mentioned earlier, DKA is an acute life threatening complication of DM. According to Harrison's Principles of Internal Medicine (19 $9^{\text {th }}$ edition), the blood sugar range in DKA is $250-600 \mathrm{mg} / \mathrm{dL}$ and HHS $600-1200 \mathrm{mg} / \mathrm{dL}$. ${ }^{1}$ The highest recorded blood sugar level in the world is 2,656 mg/dL. This value belongs to Michael Patrick Buonocore, a type $1 \mathrm{DM}$ patient, when he was admitted to the Pocono Emergency Room in East Stroudsburg, Pennsylvania, USA, on 23 March 2008. This value has enabled him to enter the Guinness Book of World Records. Our patient presented with hyperglycemia, ketosis and metabolic acidosis, thus satisfying the diagnosis of DKA; with missed insulin and urinary infection being the precipitating factors. Her blood sugar level at the time of admission was $1985 \mathrm{mg} / \mathrm{dL}$. A medical literature search does not report such an elevated blood sugar levels in DKA patients with type 2 DM. This case, therefore, highlights the recording of such a high sugar levels in an elderly patient with type $2 \mathrm{DM}$ and her miraculous survival from DKA.

Key words: Diabetic ketoacidosis, Diabetes mellitus, Urinary tract infection 


\section{Manoj Gopalakrishnan', Robin George Manappallil², Dipu Ramdas², JishnuJayaraj ${ }^{3}$}

${ }^{1}$ Senior Consultant-Physician, ${ }^{2}$ Consultant-Physician, ${ }^{3}$ Resident, Department of Internal Medicine, Baby Memorial Hospital, Calicut, Kerala, India

\section{Address for correspondence:}

Dr. Robin George Manappallil, Department of Internal Medicine,
Baby Memorial Hospital, Calicut, Kerala 673004, India E-mail: drrobingeorgempl@gmail.com, Phone: 0091-8547753396

\section{REFERENCE}

1. Powers AC. Diabetes Mellitus: Management and Therapies. In: Kasper, Fauci, Hauser,Longo, Jameson, Loscalzoeds. Harrison's Principles of Internal Medicine. $19^{\text {th }}$ ed. McGraw Hill education 2008. pp. 2417-2420.

Authors Contribution:

MG- Concept and design of case report and treating Physician; RGM- Reviewed the literature, manuscript preparation and treating Physician;

DK- Critical revision of manuscript and treating Physician; JJ- Resident in-charge

Dr. Robin George Manappallil - (D) http://orcid.org/0000-0003-3973-6800

Source of Support: Nil, Conflict of Interest: None declared. 